\title{
Analysis of the Influence of Blast Volume on Iron Oxide Melting Position by Temperature Gradient
}

\author{
XIAOLEI ZHOU ${ }^{1 *}$, ZHE SHI ${ }^{1,2}$ \\ ${ }^{1}$ Faculty of Metallurgical and Energy Engineering, Kunming University of Science and Technology, Yunnan Kunming \\ 650093 China \\ ${ }^{2}$ Clean Metallurgy Key Laboratory of Complex Iron Resources, Kunming University of Science and Technology, Yunnan \\ Kunming 650093 China
}

\begin{abstract}
COREX melting gasifier is key equipment for the natural iron oxide treatment process. However, in many published patents and documents [1-4], the description of the internal structure of the melter - gasifier is inconsistent. A physical thermal model was established in this study. Paraffin simulated iron oxide. Corn particles simulated coke. The air temperature in this model was measured with temperature sensors in different experimental conditions. The results showed the regions of the packed bed, cohesive zone, drip zone and raceway in melter gasifier could be roughly distinguished by temperature gradient analysis along the vertical direction. At the same time, this paper analyzes the change trend of the distance from the cohesive zone to the material surface in the furnace under different blast volume conditions.
\end{abstract}

Keywords: Temperature Gradient, Gasifier, Thermal Model, Blast Volume, Iron Oxide Melting

\section{Introduction}

Melting gasifier is key equipment for the natural iron oxide treatment process. An ultrahigh temperature gasifier with an annular oxygen blowing tuyere is arranged at the lower part of the gasifier. Its main function is to make oxygen coal gas, heat supply, pre-reduction of iron oxide melting, final reduction and molten iron carburizing. Inside the COREX melter gasifier, there may be an upper space expansion zone, a packed bed zone, a cohesive zone, a tuyere raceway zone, a coke fixed bed, a dead material column zone and a slag and iron water zone from top to bottom. However, in many published patents and documents [1-4], the description of the internal structure of the melter - gasifier is inconsistent.

Because the previous research on gasifier is less, the physical simulation method of blast furnace is used for reference in this paper. Physical simulation of blast furnace mainly includes cold state simulation and hot state simulation [5].

In the cold simulation, the air flow distribution in the model was investigated by artificially setting the cohesive zone.

Chen [6] established a two-dimensional model for an Angang blast furnace, and the soft-melt zone, gas permeability, gas flow distribution, and charge composition in the blast furnace was explored. Wu [7] established a cold model with the ratio of the model to the actual blast furnace size ratio of 1:30. The variation of the static pressure and pressure drop intensity of the furnace body during the process of blast furnace ironmaking with different cohesive zones was studied. The cohesive zones in the cold model is artificially preset, suitable for the specific cohesive zones forms. And it was difficult to provide the positions and shapes of the different cohesive zones formed when the operating conditions were changed.

In the thermal simulation, a substance with a low melting point is selected instead of iron oxide. When blowing hotter temperature air into the model, the simulated iron oxide is melting to form a cohesive zone. Tadashi Fukuda [8] made a thermal model based on Muram 4 blast furnace.

\footnotetext{
*email: zhouxiaolei81@163.com
} 
Paraffin simulated iron oxides. The front of the model was equipped with double glass for observation of the internal state during the experiment. Temperature measurement points were set on the back and sides of the model. The cloth device was an adjustable baffle plate. The material was discharged from the lower part at the specified speed. The results of the study indicate the corresponding relationship between charge distribution, heat flow ratio, air flow rate, high temperature performance of the iron oxide and the shape of the cohesive zone. Tamura Kenji [9] produced a twodimensional thermal model from the tuyere to the upper end of the furnace based on the second blast furnace in the Jie plant. The condition in the furnace was observed by the heat-resistant glass in front of the model. This method was used to indicate the relationship between wind temperature, air volume, ore-to-coal ratio, and lower filler (including soft-melt zone). Fukushima [10] measured temperature, pressure, and resistance at the same time during the experiment. When all the measurements were completed, the disintegration investigation was conducted. The research results indicated that changing the distribution of iron oxides can change the shape of the cohesive zone tape.

In this paper, a physical physics experiment of a melter-gasifier was established. A method for determining the position of the cohesive zone in a melter-gasifier using a temperature gradient was developed. The extent of the packed bed, the cohesive zone, and the semicoke bed in the meltergasifier was judged. Finally, this method was used to analyze the change trend of the position of the cohesive zone in the furnace under different blast volume conditions.

\section{Melting Gasifier Hot Physical Experiment}

\subsection{Experimental Device}

The experimental system is shown in Figure 1. It includes a blower, a gas flow meter, a heat fan, an air distributor, a physical model, a temperature transmitter and a computer.

The internal dimensions of the experimental model were reduced according to the internal geometry of the vertical section of the Baosteel COREX melt gasifier and the ratio was 1:30. The whole model is a stainless steel structure. The asbestos insulation layer is installed in the sandwich of the model. The front of the model is equipped with a double-layer tempered heat-resistant glass as the observation panel, which can keep warm. There are 100 temperature measurement holes on the back of the model. The thermocouple inserts into the model $15 \mathrm{~mm}$ through the temperature measurement hole. The temperature data is saved by the computer. Two tuyeres on each side of the model are inserted through the side walls. The tuyere is inclined $4^{\circ}$ downwards and is $2 \mathrm{~mm}$ deep into the furnace. Hot air is allowed in the tuyere. The gas pipe connected to the tuyere is surrounded by insulating material. The top of the model is equipped with a device for arranging materials. The bottom of the model is equipped with a discharge device. The discharge device includes a mechanical transmission mechanism and a furnace bottom baffle. It can control the model discharge speed. It can control the discharge speed evenly and smoothly. The dead material column is set in the model. The position and shape of the dead material column are set according to actual production experience.

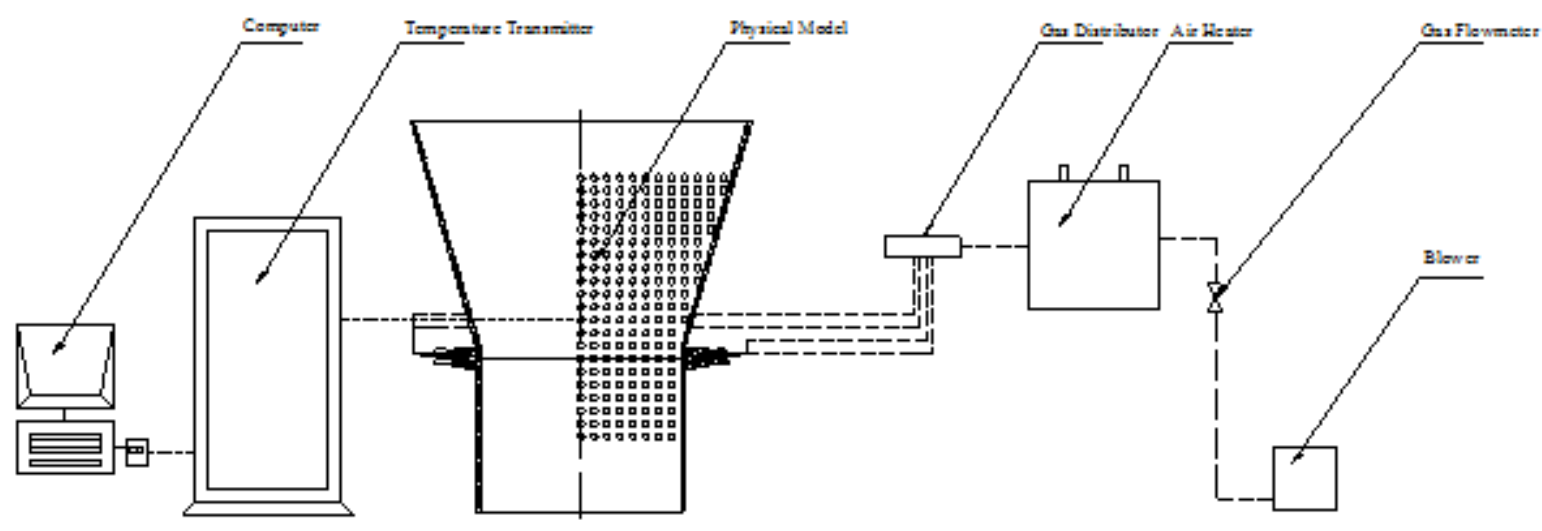

Figure 1. Experimental system 


\subsection{Experimental materials}

In this experiment, $3 \mathrm{~mm}$ paraffin particles was used to simulate iron oxide and $3 \mathrm{~mm}$ corn kernels was used to simulate lump coal and coke. The two materials were mixed into the model according to the volume ratio of iron oxides and carbon-containing materials in actual production. The model tuyere was blown into hot air. The temperature of the added material continued to rise during the descent. Paraffin particles were gradually soften and melt. When the temperature was high enough, paraffin particles were melted to form drops of paraffin droplets. Paraffin droplets enter the hearth. Finally, droplets were continuously discharged from below the model. The physical properties of the materials were shown in Table 1.

Table 1. Physical properties of materials

\begin{tabular}{cc}
\hline Items & Parameters \\
\hline Diameter of wax $(\mathrm{mm})$ & 3 \\
Diameter of maize $(\mathrm{mm})$ & 3 \\
Bulk density of wax particle $\left(\mathrm{kg} / \mathrm{m}^{3}\right)$ & 480 \\
Bulk density of maize particle $\left(\mathrm{kg} / \mathrm{m}^{3}\right)$ & 800 \\
Heat capacity of wax $(\mathrm{kJ} /(\mathrm{kg} \cdot \mathrm{K}))$ & 3.2 \\
Heat capacity of maize $(\mathrm{kJ} /(\mathrm{kg} \cdot \mathrm{K}))$ & 1.735 \\
Melting range of wax $\left({ }^{\circ} \mathrm{C}\right)$ & $58-60$ \\
Latent heat of wax $(\mathrm{kJ} / \mathrm{kg})$ & 101.5 \\
\hline
\end{tabular}

\subsection{Experimental scheme}

Based on the actual smelting rate of the production, the model discharge rate was calculated. The blast volume was calculated using the Froud number [11,12]. According to the model material balance and the heat balance, the tuyere was blown into the hot air temperature. In order to observe more obvious experimental results, the range of experimental parameters such as model air volume was appropriately expanded, based on the reference calculation data. The specific parameters are shown in Table 2.

Table 2. Parameters of physical experiments

\begin{tabular}{|c|c|c|c|c|c|}
\hline $\begin{array}{c}\text { Burden height } \\
(\mathrm{cm})\end{array}$ & $\begin{array}{c}\text { Burden temperature } \\
(\mathrm{C})\end{array}$ & $\begin{array}{c}\text { Discharge rate } \\
\left(\mathrm{dm}^{5} / \mathrm{h}\right)\end{array}$ & $\begin{array}{c}\text { Volume ratio of wax to } \\
\text { maize }\end{array}$ & $\begin{array}{c}\text { Blast temperature } \\
(\mathrm{C})\end{array}$ & $\begin{array}{c}\text { Blast volume } \\
\left(\mathrm{m}^{3} / \mathrm{h}\right)\end{array}$ \\
\hline 27 & 20 & 2.2 & 0.5 & 100 & $10,14,18$ \\
\hline
\end{tabular}

\section{Using Temperature Gradient to Judge the Cohesive Zone in the Furnace}

Through preliminary experiments, a longitudinal thermocouple in the middle of the axis of the model and the center line of the side wall was selected as a representative to study the variation of the longitudinal temperature inside the gasifier. The thermocouple position is shown in Figure 2. The temperature data is recorded when the hot air is sent and collected every $1 \mathrm{~s}$. The thermocouple is in point contact with the particles inside the model and is surrounded by gas mainly. Therefore, the thermocouple measured data can be considered as the temperature of the gas.

The following experiments were performed with certain conditions (air volume $14 \mathrm{~m}^{3} / \mathrm{h}$, air temperature $100{ }^{\circ} \mathrm{C}$, material height $270 \mathrm{~mm}$, volume ratio of ore/(lump coal + coke) 0.5:1, discharge rate $2.2 \mathrm{dm}^{3} / \mathrm{h}$ ) as an example. And experimental data was analyzed and processed. 

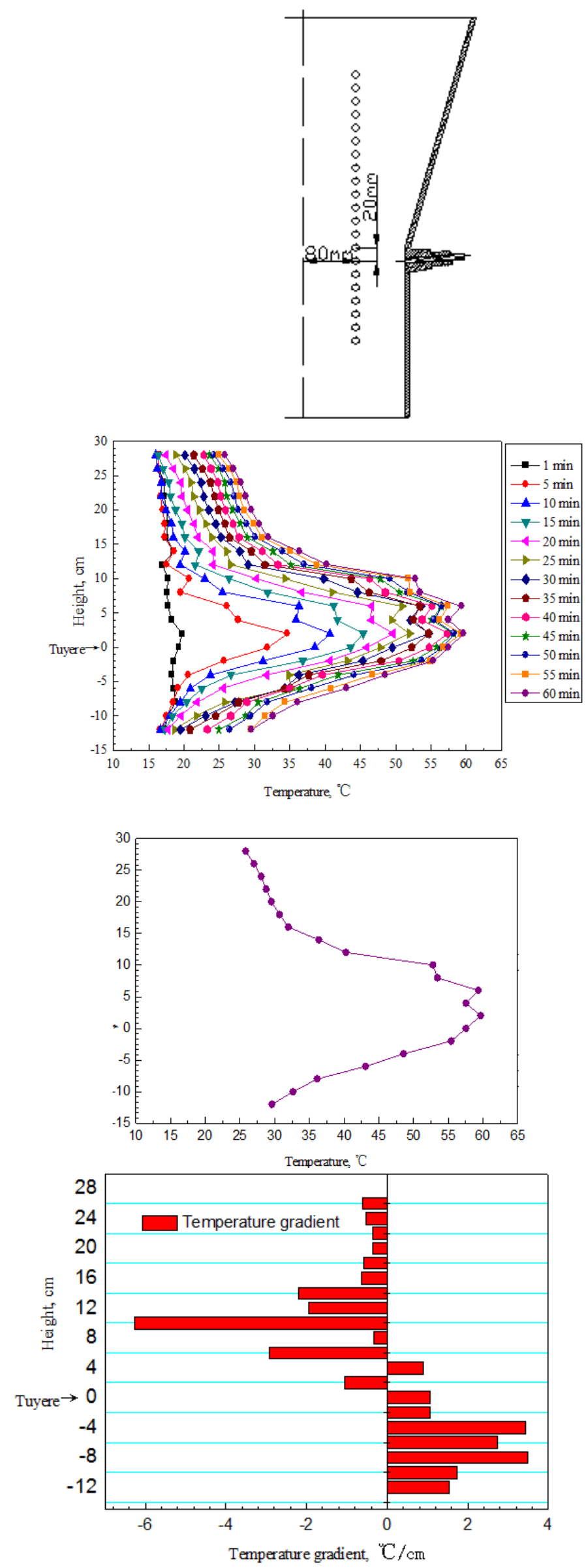

Figure 2.

Position of thermocouples
Figure 3. Temperatures of thermocouples on the vertical changes with time
Figure 4. Temperature of thermocouple at $60 \mathrm{~min}$
Figure 5. Gas temperature gradient in the vertical direction 
Vertical thermocouple temperature changes with time as shown in Figure 3. The height of the tuyere is $0 \mathrm{~cm}$. When the experiment was carried out for 35 minutes, the phenomenon that temperature gradients in the interior of the gasifier was basically uniform was found. This method can be used to analyze the various zones of the gasifier.

In order to obtain a clear gradient trend, the temperature data at $60 \mathrm{~min}$ is selected. The experimental data is shown in Figure 4. The calculated temperature gradient is shown in Figure 5. With the observation of the situation in the model, each zone is analyzed from top to bottom.

(1) Between the height of the model $16-27 \mathrm{~cm}$, the absolute value of the gradient of the gas temperature with height changes is about 0.5 . And the gradient value does not change much, and it is inferred that this zone is a packed bed zone. In this zone, the heat carried by the gas is mainly used for the warming of corn and paraffin particles.

(2) Between the height of the model $12-16 \mathrm{~cm}$, the absolute value of the gradient of the gas temperature with height changes is about 2. It is inferred that the paraffin in the material begins to soften. In this zone, a small portion of paraffin particles begins to melt. A portion of the heat carried by the gas is used to warm up the pellets of corn and wax, and the other part is used to melt less paraffin particles.

(3) Between the height of the model $10-12 \mathrm{~cm}$, the absolute value of the gradient of the gas temperature with height changes is about 8 . It is inferred that this zone is a cohesive zone. In this zone, part of the heat carried by the gas is used to warm up the corn grain, and part of it is used to melt more paraffin particles. Paraffin wax absorbs a lot of heat during the melting process and has the highest gradient absolute value.

(4) Between the height of the model $8-10 \mathrm{~cm}$, the absolute value of the gradient of the gas temperature with height changes is about 0.5 . This value is similar to the gradient of the height of the gas temperature in the packed bed region. It is inferred that this zone is a semi-coke bed. In this zone, there are only corn particles and no paraffin particles. The heat carried by the gas is only used to increase the temperature of the corn granules.

(5) Between the height of the model $-2-8 \mathrm{~cm}$, the gas temperature in this zone is high. The tuyere is in this zone. It is inferred that this zone is a tuyere raceway. In this zone, a raceway cavity is formed. The high-speed movement of corn particles can be seen in the cavity. The main air flow in the raceway moves along the edge of the raceway. This phenomenon causes the center temperature of the raceway to be lower than the edge temperature.

(6) Because the model is not considered heat insulation at the bottom of the hearth at the time of design. Therefore, the temperature data between the heights of -10 and $18 \mathrm{~cm}$ is limited meaning and it is not analyzed.

By analyzing the temperature gradient, the approximate range of the packed bed zone, the cohesive zone, the semi-coke bed, and the tuyere raceway zone in the melter-gasifier can be inferred. Therefore, this method can be used to further analyze the effect of different operating conditions on the range changes in the interior of the melter-gasifier.

\section{The İnfluence of Blast Volume on the Position of Cohesive Zone}

It can be seen from the observation of Figure 6 that the simulation of iron oxide exhibits a certain regularity in the model. With the increase of air volume, the temperature of each zone in the model rises. The size of the raceway increases, the position of the cohesive region rises, and the range of the cohesive region increases. When the blast volume was $18 \mathrm{~m}^{3} / \mathrm{h}$, some phenomena were observed that frequent collapse occurred in the raceway and recovered quickly after the collapse. The reason for this phenomenon is that the blast volume is too large, the destructiveness of the airflow to the material bed is too large, the semi-coke bed is too thin, the strength of the semi-coke bed is reduced, the supporting force is reduced, and the collapse phenomenon occurs. 


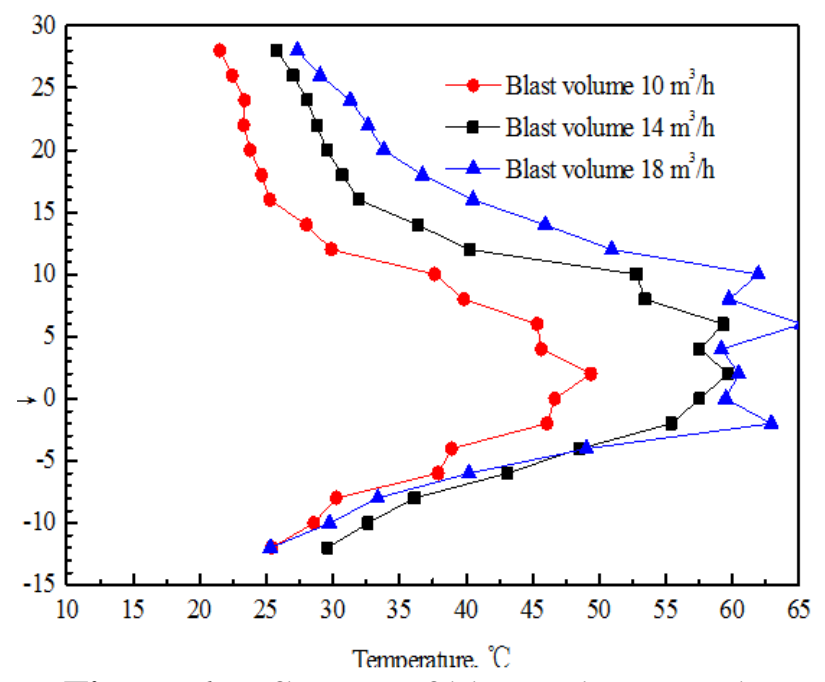

Figure 6. Influence of blast volume on the temperature in the vertical direction

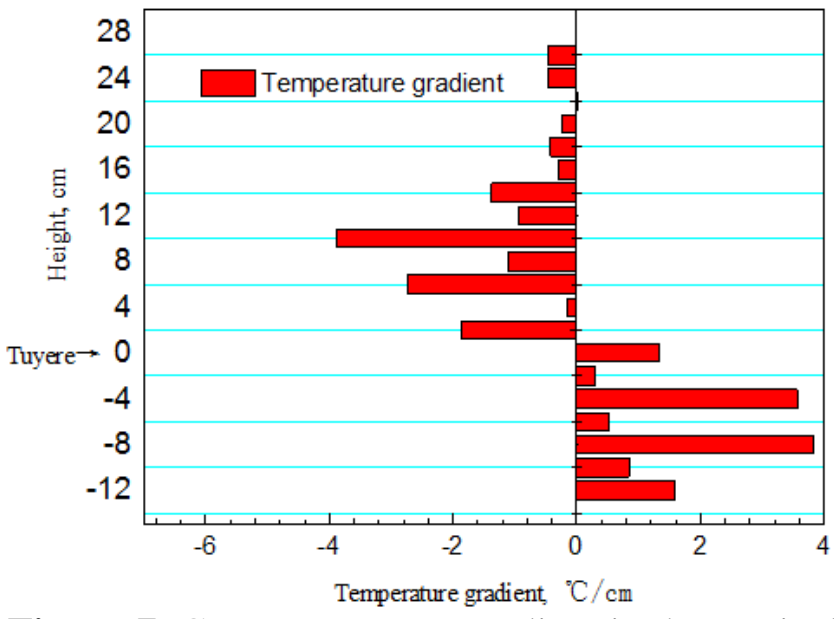

Figure 7. Gas temperature gradient in the vertical direction at $10 \mathrm{~m} 3 / \mathrm{h}$ blast volume

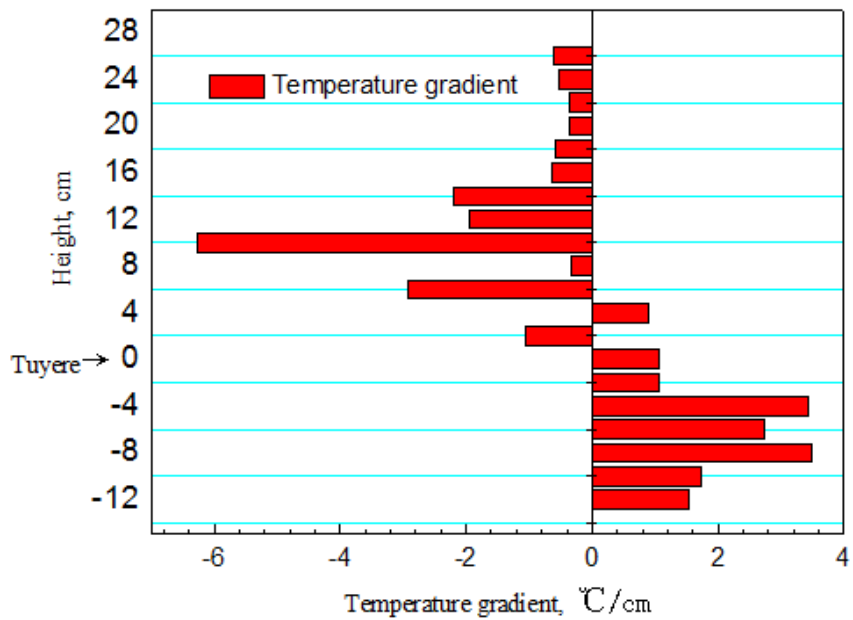

Figure 8. Gas temperature gradient in the vertical direction at $14 \mathrm{~m} 3 / \mathrm{h}$ blast volume 


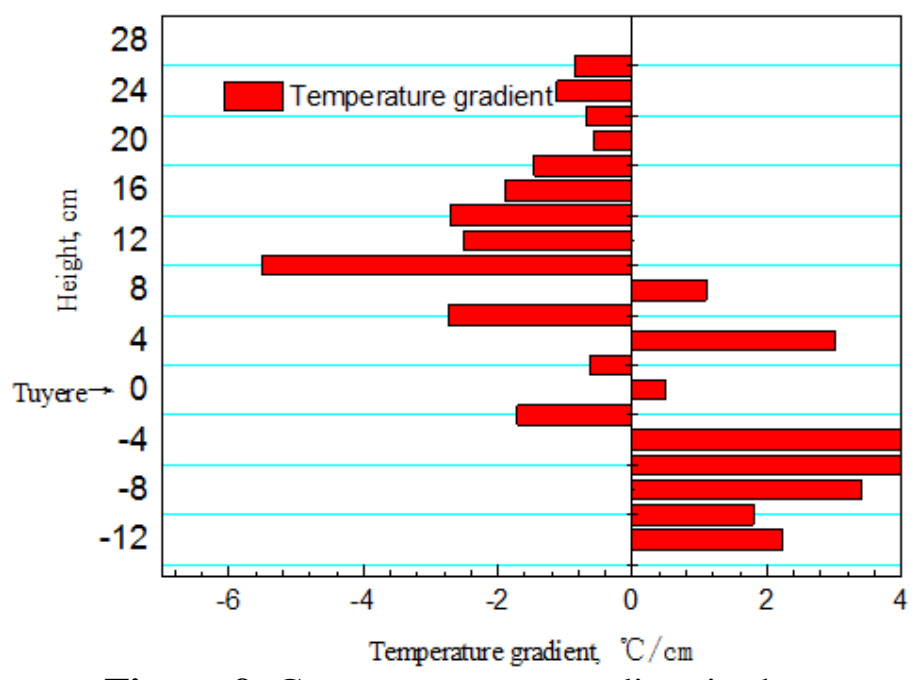

Figure 9. Gas temperature gradient in the vertical direction at $18 \mathrm{~m}^{3} / \mathrm{h}$ blast volume

By observing Figure 7, Figure 8 and Figure 9, it can be found that the morphogenetic transformation of iron oxide mimics occurred in the model. With the increase of blast volume, the melting strength in the cohesive zone in the model increased from 4 to 6 , and the pre- cohesive range increased from $4 \mathrm{~cm}$ to $8 \mathrm{~cm}$. Due to the effect of the collapse phenomenon, the melt strength of the cohesive zone when the blast volume is $18 \mathrm{~m}^{3} / \mathrm{h}$ is slightly lower than when the blast volume is 14 $\mathrm{m} 3 / \mathrm{h}$. The increase in blast volume has little effect on the temperature gradient in the uppermost packed bed zone. This shows that the increase in blast volume did not lead to the occurrence of simulant softening and melting in the zone.

\section{Conclusions}

The regions of the packed bed, cohesive zone, drip zone and raceway in melter gasifier could be roughly distinguished by temperature gradient analysis along the vertical direction. At the same time, this paper analyzes the change trend of the distance from the cohesive zone to the material surface in the furnace under different blast volume conditions. But limited by experimental conditions, this research also has some shortcomings. Future experiments should pay more attention to the influence of gas expansion and contraction with temperature change. At the same time, greatly extending the experimental time should be considered. A natural dead column is formed inside the model. This is the future development direction of this experiment.

Acknowledgments: This work was supported in part by a grant from fund Projects. Project funded by the Ministry of Education of Yunnan Province KKJB201752017; Industrial Development Project of Yunnan Provincial Department of Education Science Research Fund 2016CYH07;Yunnan Science and Technology Plan Project 2017ZE033

\section{References}

1.LI HAIFENG, WANG CHEN, ZOU ZONGSHU. Steady state numerical simulation of COREX melting gasifier[J]. Baosteel Technology. 2008(6), 19-22.

2.SUBRATA PAL, ASHOK KUMAR LAHIRI. Mathematical Model of COREX Melter Gasifier: Part I. Steady-State Model[J]. METALLURGICAL AND MATERIALS TRANSACTIONS B, 2003, 34B (2): 103-114.

3.SEUNG CHEOL LEE, MYUNG KYUN SHIN, SANGHOON JOO, JONG KYU YOON. A Development of Computer Model for Simulating the Transport Phenomena in COREX Meltergasifier[J]. ISIJ International, 1999, 39(4), 319-328. 
4.SEUNG-CHEOL LEE, MYUNG-KYUN SHIN, SANGHOON JOO, JONG-KYU YOON. The Effects of Operational Parameters on the Transport Phenomena in COREX Melter-Gasifier[J]. ISIJ International, 2000, 40(11), 1073-1079.

5.ZHONG WEIGUO, JI FUZHONG. Study on the testing method of soft-melt zone morphology [J]. Baotou Steel Technology, 1983, (4): 44-50.

6.CHEN SHICHAO, LI WENZHONG, DU RONGSHAN. Experimental Study on Gas Mechanical Model of Blast Furnace Remelted Zone [J]. Iron and Steel, 1981,16(7):62-65.

7.WU WENHUA, SONG JIANCHENG, JIA YINLONG. Study on Cold Simulation of Gas Mechanics in Blast Furnace Soft-melt Zone [J]. Iron and Steel Research, 1993, (6): 38-42.

8.TOSHIYUKI IIDA, TADASHI ISOYAMA, YOSHIAKI HARA, etc. Studies on the formation behavior of fusion bonds by model experiments [J] Iron and Steel, 1982, 68 (15): 2295-2302.

9.KAMI TAMURA, MASAMORI MASAMORI, AKATSUYA, etc. Study on the lowering behavior of blast furnace bottom filling by two dimensional model [J]. Steel and Steel, 1984, 70 (10): A 141 - A 144.

10.FUKUSHIMA, OONO YOTARO, NAOKI TOSHIO, etc. Studies on blast furnace melting zone by pseudo-hot model [J]. Steel and steel, 1982, 68 (4): S112.

11.HIROSHI TAKAHASHI, NOBUYUKI KOMATSU. Cold model study on burden Behaviour in the lower part of blast furnace[J]. ISIJ International, 1993, 33(6): 655-663.

12.HIROSHI TAKAHASHI. MASAYUKI TANNO, JIRO KATAYA. Burden Descending Behaviour with Renewal of Deadman in a Two Dimensional Cold Model of Blast Furnace ISIJ International, 1996, 36(11), 1354-1359.

Manuscript received: 19.03 .2020 